\title{
Investigation and Research on the Professional Ethics of Kindergarten Teachers in Shenyang
}

\author{
Lina Zhang ${ }^{1}$, Dongqing $\mathrm{Bai}^{1}$, Ailing $\mathrm{Yu}^{2}$ \\ ${ }^{1}$ Teachers' College, Shenyang University, Shenyang, China; \\ ${ }^{2}$ Kindergarten affiliated to Anying Primary School, Shenyang, China.
}

Keywords: Kindergarten teacher; professional ethics; investigation and research

Abstract. This paper takes the teachers of 8 kindergartens in Shenyang as the survey object, analyzes the current situation and existing problems of kindergarten teachers' professional ethics through questionnaires and interviews, and proposes corresponding solutions to the existing problems, that is, teachers should improve their professional ethics, kindergarten managers should improve their professional ethics, kindergartens should strengthen the construction of teachers' professional ethics, improve the teacher's professional ethics training system, and provide a theoretical reference for kindergarten teachers' professional ethics construction.

\section{Definition of Related Concepts}

\subsection{Kindergarten teacher}

The definition of kindergarten teachers in this paper is mainly from three aspects: professional identity, job responsibilities and career manifestation ${ }^{[1]}$. First of all, the professional identity of kindergarten teachers is professional, and kindergarten teachers must pass relevant professional training and obtain qualification certificates before entering the job. Secondly, the role of kindergarten teachers is to educate and teach young children and directly assume the actual educational and teaching responsibilities. Finally, kindergarten teachers need educational activities in kindergartens or other preschool education institutions before they can become kindergarten teachers.

\subsection{Professional ethics}

The definition of professional ethics in "Ci Hai" is a part of social morality, a manifestation of social morality, and a moral norm that members of society need to abide by in their own professional activities.

\subsection{Professional ethics of kindergarten teachers}

Professional ethics of kindergarten teachers refers to the professional ethics standards that kindergarten teachers must abide by in the process of teaching early childhood education and the professional knowledge and moral cultivation required for the special nature of early childhood education, as well as the attitude towards the kindergarten teacher, career ideals, love, and care for young children ${ }^{[2]}$.

\section{Investigation on the Present Situation of Professional Ethics of Kindergarten Teachers in Shenyang}

\subsection{Survey design}

\subsubsection{Purpose of investigation}

The status quo and problems of kindergarten teachers' professional ethics in Shenyang City were analyzed and researched, and corresponding suggestions were made to improve the overall level of kindergarten teachers' professional ethics.

\subsubsection{Survey respondent}

Investigators were selected from 8 kindergartens in Shenyang (Qidian kindergarten, Wutong kindergarten, Jindoudou kindergarten, Xinxin kindergarten, Minjin kindergarten, Guihe kindergarten, Yude kindergarten, Sibo Rui kindergarten).

\subsubsection{Survey content}

This thesis divides the kindergarten teachers' professional ethics into four aspects: love and dedication, love of students, rigorous scholarship, and teacher-management. Through the investigation and analysis 
of these four dimensions, the status quo and problems of kindergarten teachers' professional ethics are studied.

\subsubsection{Survey methods}

Questionnaire survey: Eight kindergartens in Shenyang were selected to conduct questionnaire surveys. A total of 160 questionnaires were distributed, 156 questionnaires were returned, and 155 valid questionnaires were obtained. The recovery rate was $97.5 \%$ and the effective rate was $99.3 \%$.

Interview method: 8 kindergarten teachers in Shenyang were selected as interviewees to understand the professional ethics and supplement the results of the questionnaire survey.

\subsection{Status analysis}

2.2.1 Devotion and dedication of kindergarten teachers

Table 1 Situation of kindergarten teachers' devotion and dedication in Shenyang

\begin{tabular}{cccc}
\hline & Yes & No & Not clear \\
\hline Love the preschool education & $72 \%$ & $15 \%$ & $13 \%$ \\
Work motivation & $87 \%$ & $7 \%$ & $6 \%$ \\
Devotion and dedication & $63 \%$ & $14 \%$ & $23 \%$ \\
\hline
\end{tabular}

As can be seen from Table 1, 72\% of the teachers said that they loved the profession of preschool teachers, only $15 \%$ of the teachers thought that they did not like the preschool teachers and another $13 \%$ of the teachers did not know whether they love the preschool education. About the enthusiasm of work, $87 \%$ of teachers believe that their work attitude is positive, and only $7 \%$ of teachers believe that their work attitude is relatively negative. In terms of dedication, $63 \%$ of teachers are determined to be dedicated, 23\% are uncertain, and 14\% lack dedication.

2.2.2 Conditions of kindergarten teachers' love for children

Table 2 Conditions of kindergarten teachers' love for children in Shenyang

\begin{tabular}{c|c|c|c}
\hline & Yes & No & Not clear \\
\hline Care for young children & $92 \%$ & $6 \%$ & $2 \%$ \\
\hline Extend the same treatment to all & $69 \%$ & $20 \%$ & $11 \%$ \\
\hline Respect for young children & $86 \%$ & $2 \%$ & $12 \%$ \\
\hline
\end{tabular}

As can be seen from Table 2, 92\% of teachers can care for young children. Teachers' love for young children is the driving force that drives them to work consciously. In terms of same treatment to all, the performance of kindergarten teachers is not ideal, and $20 \%$ of teachers cannot treat all children equally. On the issue of being able to respect young children, $86 \%$ of teachers believe that they can fully respect young children at work, and they will not ignore their right to express because their children are too young.

2.2.3 Conditions of rigorous scholarship of kindergarten teachers

Table 3 Conditions of rigorous scholarship of kindergarten teachers in Shenyang

\begin{tabular}{c|c|c|c}
\hline & Yes & No & Not clear \\
\hline Reflection and learning & $74 \%$ & $18 \%$ & $8 \%$ \\
\hline Active innovation & $57 \%$ & $39 \%$ & $4 \%$ \\
\hline Good research attitude & $49 \%$ & $44 \%$ & $7 \%$ \\
\hline
\end{tabular}

As can be seen from Table 3, 74\% of teachers indicated that they would reflect on learning in a timely manner, and $18 \%$ and $8 \%$ of kindergarten teachers indicated that they would not reflect on learning or were unclear. In terms of active innovation, $57 \%$ of kindergarten teachers will innovate frequently, while teachers who do not actively innovate account for 39\%. In terms of scientific research attitude, $44 \%$ of teachers lack interest in teaching and research and lack research enthusiasm. From the results of the interviews, the innovative ability of kindergarten teachers is mainly reflected in the innovation of teaching 
forms, class management, and kindergarten environment creation. Many innovative achievements have improved teaching efficiency and facilitated class management.

2.2.4 Conditions of being a model of virtue for others of kindergarten teachers

Table 4 Conditions of being a model of virtue for others of kindergarten teachers in Shenyang

\begin{tabular}{c|c|c|c}
\hline & Yes & No & Not clear \\
\hline Lead by example & $93 \%$ & $5 \%$ & $2 \%$ \\
\hline Unity & $71 \%$ & $25 \%$ & $4 \%$ \\
\hline Emotional control & $67 \%$ & $28 \%$ & $5 \%$ \\
\hline
\end{tabular}

As can be seen from Table 4, 93\% of teachers believe that they can lead by example in education and teaching, and 5\% think they have not set a good example for children. In solidarity and cooperation, $71 \%$ of teachers believe that they have established good cooperation with colleagues and parents, and $25 \%$ of teachers believe that their cooperation with parents or teachers is not close enough. In emotional control, $28 \%$ of preschool teachers do not have good control over their negative emotions and bring their negative emotions into their work.

\section{Problems in the Professional Ethics of Kindergarten Teachers $n$ Shenyang}

\subsection{Some teachers have defects in their professional ethics}

Judging from the results of questionnaire surveys and interviews, some kindergarten teachers in Shenyang have lower professional ethics, including lack of impartial awareness, innovation and poor scientific research attitude. In practice, many teachers cannot treat every child fairly and fairly. Usually, extroverted, lively, and intelligent children will get more performance opportunities, while introverted, shy, and reticent children have very few opportunities for self-expression. Moreover, some teachers can't correctly treat innovation problems. At work, they prefer to follow the rules and are reluctant to change the way of education and class management with the development of the times, and continue to adopt traditional teaching methods. In addition, in the attitude towards scientific research, a considerable number of teachers do not correctly recognize the significance and value of scientific research. They only regard it as a task of work, as an additional burden, and lack the motivation to participate in teaching and research, resulting in unsatisfactory results.

\subsection{Teachers themselves do not pay attention to professional ethics}

It can be seen from the survey that some teachers do not pay enough attention to the construction of professional ethics, and believe that the cultivation of professional ethics is not as important as the promotion of professional skills. This one-sided cognition seriously hinders the development of kindergarten teachers' professional ethics. Moreover, teachers do not have enough understanding of the specific content of professional ethics. They did not recognize the requirements of professional ethics for teachers to reflect on learning, continuous innovation, scientific research awareness, and lead by example, and lack of understanding of the specific practice of professional ethics.

\subsection{Kindergarten does not pay attention to teachers' professional ethics}

It can be seen from the survey that kindergartens lack attention to the cultivation of teachers' professional ethics, which is reflected in the lack of corresponding kindergarten teachers' professional assessment and targeted training. On the one hand, kindergarten managers do not pay much attention to the professional ethics of teachers, but pay more attention to the actual teaching ability of teachers and value teaching results. Such a management concept will inevitably lead to a lack of professional ethics in kindergartens. On the other hand, there are fewer relevant assessment measures for teachers' professional ethics, which leads to teachers' lack of external motivation to improve their professional ethics. As a result, many teachers only attach importance to improving their teaching ability and neglect the development of professional ethics. 


\subsection{Kindergarten teachers' professional ethics training system is not perfect}

Kindergarten teachers' professional ethics training system is generally not perfect, and targeted professional ethics training is rare, therefore, kindergarten teachers cannot improve their professional ethics through kindergarten training. First of all, the kindergarten did not carry out the necessary needs analysis, did not investigate the shortcomings of the teachers' professional ethics in the park, and did not have enough knowledge of the formation of teachers' professional ethics. Secondly, although the pre-job training of teachers contains some content of professional ethics training, these contents are more biased towards theoretical knowledge, lack of practical operability, and are out of touch with the actual needs of teachers, so the ideal training effect cannot be achieved. Thirdly, the choice of training form is relatively monotonous, mainly adopting expert lectures and excellent teacher sharing. The training process is in the form, and kindergarten teachers lack interest in participation. Finally, the kindergarten training system generally lacks a perfect training evaluation mechanism, and can not effectively feedback the training effect to the training planner, which is not conducive to the improvement of follow-up training activities $^{[3]}$.

\section{Countermeasures for Improving the Professional Ethics of Kindergarten Teachers}

\subsection{Teachers should improve their professional ethics}

As the saying goes, learning is endless, and if you don't advance, you will retreat. Young children are constantly evolving and changing. The knowledge of education, psychology and brain science is constantly developing and progressing. All of these require teachers to actively learn, constantly update knowledge, and improve their cultivation. In addition, teachers should choose other teachers with outstanding professional ethics as examples of learning, learn their excellent qualities such as caring for young children, actively innovating, attaching importance to scientific research, and learning to reflect, and constantly improve their professional ethics. Only in this way can they complete the educational task better and become a qualified teacher and become a good teacher.

\subsection{Managers should improve their professional ethics}

To achieve the goal of "management and education", managers must effectively improve their overall quality in order to make a difference. Professional ethics is the code of conduct that all managers should follow in their professional activities. As a kindergarten management worker, it is necessary to strictly demand professional ethics and set an example. First of all, kindergarten managers should lead by example, actively practice professional ethics, establish a model and role model for teachers, and strive to create an atmosphere of professional ethics in the park to improve teachers' professional ethics. At the same time, it is necessary to increase the humanistic care for teachers, pay attention to the work of teachers, and timely guide the psychological pressure of teachers to prevent teachers from venting negative situations in the classroom ${ }^{[4]}$.

\subsection{Kindergartens should strengthen the construction of teachers' professional ethics}

To strengthen the construction of teachers' professional ethics, kindergartens should insist on the construction of teachers' morality in the prominent position of the construction of teachers. First of all, kindergartens should regularly carry out teachers' professional ethics education activities, and improve the overall teacher morality of kindergarten teachers through a series of activities. When the teacher's moral education activities are carried out, the goal should be clarified, combined with the teacher's teaching practice to highlight the teaching focus and improve the effectiveness of teacher's moral education. Secondly, kindergartens should start from the perspective of long-term planning, establish a long-term mechanism for teacher moral education, and improve the mechanisms for the operation, supervision, assessment, rewards and punishments, etc., take the teacher's morality as one of the indicators of the teacher's comprehensive assessment, regard the results of the teacher's moral examination as the main reference factor for teachers' promotion and evaluation and implement a "one-vote veto" for teachers who have serious defects in their teachers' morality. 


\subsection{Kindergartens should improve the teacher's professional ethics training system}

In order to conscientiously improve the professional ethics training of teachers and complete the training tasks to improve the educational theory level and professional quality of teachers, kindergartens should formulate the training system for the local affairs in accordance with the provisions of the Regulations on the Promotion of Private Education of the People's Republic of China. First of all, the training objectives of teachers' professional ethics should be clarified, and the training needs of teachers should be clarified in light of the specific conditions of kindergartens. Secondly, the content of the training should be adjusted reasonably, and the theoretical knowledge and practical operation should be reasonably combined to make the training content better guide the educational practice and improve the training effect. Thirdly, the vivid and diverse forms of training rather than a boring and single one should be reasonably selected, such as case analysis, apprenticeship, etc. to improve the professional ethics of kindergarten teachers ${ }^{[5]}$.

\section{Conclusion}

The level of professional ethics of kindergarten teachers directly affects the healthy development of many aspects such as society, kindergartens, teachers and children. This thesis explores the status quo of kindergarten teachers' professional ethics through questionnaire survey and interview method, and proposes corresponding solutions to the existing problems, that is, teachers should improve their professional ethics, kindergarten managers should improve their professional ethics, and kindergartens should strengthen teachers' professional ethics, and improve teachers' professional ethics training system. In this paper, only 8 kindergartens in Shenyang were selected as the survey objects. The number of samples was small, the survey results lacked sufficient representativeness, and the discussion on teachers' professional ethics was not deep enough.

\section{References}

[1] Qian Huanqi. Teacher Professional Ethics [M]. East China Normal University Press, 2016.

[2] Zou Cuizhen. Discussion on the Construction of Preschool Teachers' Professional Ethics[J]. Pearl River Education Forum, 2017(1): 21-23.

[3] Li Lizhen. The Status Quo, Problems and Countermeasures of Preschool Teachers' Moral Assessment[J]. Economic Research Guide, 2017(30): 145-146.

[4] Zhou Haiyan. Research on the Strategy of Promoting the Construction of Preschool Teachers' Morality with Humanized Management[J]. Children's World Monthly, 2017(3).

[5] Zhai Dunfeng, Dai Jun, Ye Lin. Research on the Status Quo, Problems and Countermeasures of Preschool Teachers' Professional Ethics[J]. Journal of Hubei Teachers College (Philosophy and Social Sciences), 2017, 37(1): 131-134. 